\title{
PENGARUH HARGA, LOKASI PENJUALAN DAN KUALITAS PRODUK TERHADAP KEPUTUSAN PEMBELIAN DODOL
}

\author{
Winda Silviana \\ Alumni Jurusan Manajemen Fakultas Ekonomi Universitas Negeri Medan \\ Saidun Hutasuhut \\ Dosen Fakultas Ekonomi Universitas Negeri Medan
}

\begin{abstract}
This study aims to determine the effect of variables of price, sales locations and product quality toward dodol purchase decisions in Tanjung Pura Langkat. The number of population in this study are 7000 consumers and the number of samples determined by Slovin formula as many as 100 people.Sampling technique used is simple random sampling. Data collected by Likert scale questionnaire. Questionnaire first tested the validity and reliability. Further data are analyzed by multiple regression. Hypotheses were tested by t-test and f test with data classical assumption tested first. Research findings are partially obtained that the price, product quality positively and significantly influence the purchase decision. However, the sales location has no effect towards the purhacasing decision. While joint test of price variables, location of sales and product quality simultaneously have a positive and significant effect on purchasing decision of dodol. 49,4\% variation in purchases of dodol is explained by the three variables. The remaining $50,6 \%$ is explained by other variables outside the research model.
\end{abstract}

Keywords : Price, Location, Product Quality, Purchase Decision

\section{PENDAHULUAN}

Dodol merupakan makanan tradisional yang dimiliki Bangsa Indonesia. Keberadaanya sekarang ini menjadi asing di Negaranya. Secara perlahan akan tergusur bahkan terancam hilang karena hadirnya makanan asing modern. Untuk mempertahankannya perlu adanya inovasi baik dalam memproduksinya maupun pemasaraannya. Dari segi produksi perlu inovasi yang dapat menekan biaya produksi agar dapat bersaing dengan makanan modern. Kemudian perlu juga diciptakan teknologi yang dapat menghasilkan dodol yang berkualitas. Selanjutnya yang tidak kalah penting adalah bagaimana memasarkan agar konsumen tetap tertarik membeli dodol.

Konsumen dalam melakukan pembelian melalui suatu proses adanya rencana atau niat. Untuk itu, perlu diketahui apa faktor yang menjadi pertimbangan konsumen sebelum memutuskan membeli dodol. Pendekatan yang paling banyak digunakan untuk memahami proses pengambilan keputusan konsumen yang kompleks adalah penggunaan teori sosio-psikologis seperti teori aksi beralasan, teori perilaku terencana (TPB), dan model perilaku yang diarahkan pada tujuan (model of goal-directed behavior $=$ MGB) (Han \& Ryu, 2012). 
Banyak faktor yang dapat mempengaruhi keputusan pembelian terhadap suatu produk, seperti pertimbangan terhadap harga, lokasi penjualan dan kualitas produk. Harga merupakan persepsi konsumen terhadap harga yang ditawarkan. Variabel harga produk dapat menentukan diterima atau tidaknya suatu produk oleh konsumen. Menurut Kotler dan Amstrong ( 2010 ) harga adalah sejumlah uang yang dibebankan atas suatu produk atau jasa, atau jumlah dari nilai yang diukur konsumen atas manfaatmanfaat karena memiliki atau menggunakan produk atau jasa tertentu. Kemudian menurut Tjiptono (2007:151) harga merupakan satuan moneter atau ukuran lainnya (termasuk barang dan jasa lainnya) yang ditukarkan agar memperoleh hak kepemilikan atau penggunaan suatu barang atau jasa. Faktor-faktor yang mempengaruhi tingkat harga menurut Swastha (2000:211) antara lain; (a) keadaan perekonomian, (b) penawaran dan permintaan, (c) elastisitas permintaan, (d) persaingan, (e) biaya, (f) tujuan perusahan, dan (g) pengawasan pemerintah.

Harga yang ditetapkan penjual menurut Tjiptono (2000:152) mempunyai beberapa tujuan yang berorientasi pada; laba, volume, citra, stabilitas harga, dan tujuan-tujuan lainnya. Tujuan yang ditetapkan harus konsisten dengan cara yang ditempuh perusahaan menempatkan posisi relatifnya dalam persaingan. Misalnya, pemilihan berorientasi pada laba mengandung makna bahwa perusahaan akan mengabaikan harga para pesaing.

Harga yang ditawarkan kepada konsumen harus terjangkau. Harga bersifat relatif, mahal atau murah tergantung dari persepsi konsumen. Untuk menyatakan harga murah atau mahal, terlebih dahulu membandingkannya dengan harga produk serupa yang dijual perusahaan lain. Oleh sebab itu, perusahaan harus menetapkan harga yang bersaing atau tidak berbeda jauh dari harga produk sejenis. Menurut pendapat Staton (2001:25) ada empat indikator yang mencirikan harga, yaitu ; (a) keterjangkauan harga, (b) kesesuaian harga dengan kualitas produk, (c) daya saing harga, dan (d) kesesuaian harga dengan manfaat.

Faktor lain yang mempengaruhi keputusan pembelian konsumen adalah pendapatan konsumen. Pendapatan yang tinggi biasanya akan diikuti dengan kemampuan daya beli yang lebih tinggi. Sebaliknya pendapatan yang rendah akan diikuti dengan kemampuan membeli yang lebih kecil. Konsumen biasanya akan membandingkan kesesuaian harga yang dibayarkan dengan kualitas produk. Menurut Grunert, K.G., (2005) konsumen ingin mendapatkan harga produk yang rendah dengan kualitas terbaik. Selanjutnya harga yang ditawarkan kepada konsumen harus sesuai dengan pandangan atas nilai dan manfaat yang didapatkan dari produk atau jasa tersebut.

Pemilihan lokasi penjualan juga perlu dipertimbangakan. Karena lokasi yang strategis atau tidak strategis akan mempengaruhi kelangsungan usaha. Sementara lokasi penjualan dodol di Tanjung Pura Kabupaten Langkat (salah satu sentra industri dodol di Sumatera Utara) cukup jauh dari perkotaan. Setyawarman, A. (2009) menyatakan kelangsungan bisnis retail sangat 
tergantung dari aksesibilitas, memperkecil cakupan pasar, sebaliknya aksesibilitas yang tinggi kemungkinan terjadi interaksi (interaction) dan pergerakan (movement) yang tinggi konsumen ke lokasi bisnis retail.

Kemudian menurut Tjipotono dan Chandra (2005) lokasi berpengaruh terhadap dimensidimensi strategi, seperti fleksibilitas, competitive, positioning, manajemen permintaan, dan fokus strategi. Fleksibilitas sebuah lokasi merupakan ukuran sejauh mana sebuah badan usaha mampu bereaksi terhadap situasi perekonomian yang berubah. Sedangkan competitive postioning adalah metode- metode yang digunakan agar usaha dapat mengembangkan posisi relatifnya dibandingkan dengan para pesaing. Jika badan usaha berhasil memperoleh dan mempertahankan lokasi yang strategis, maka itu dapat menjadi rintangan yang efektif bagi para pesaing untuk mendapatkan akses kepasar (Tjiptono dan Chandra, 2005).

Ada beberapa faktor yang harus dipertimbangkan dalam letak atau tempat usaha yaitu; (a) lalu lintas penjalan kaki, (b) lalu lintas kenderaan, (c) informasi tentang jumlah dan karakteristis kendaraan yang melintas, (d) fasiltas parkir, (e) transportasi umum, (f) letak berdirinya gerai, dan (g) penilaian keseluruhan ( Ma'ruf, $\mathrm{H}$. 2005). Hal senada disampaikan Sopiah (2008:139-140) faktor yang harus di pertimbangkan dalam pemilihan lokasi penjualan agar pembeli tertarik, yaitu; (a) lalu lintas kendaraan, (b) fasilitas parkir, (c) transportasi umum, (d) letak berdirinya tempat berjualan, dan (e) syarat dan ketentuan pemakaian ruang.

Lamb dkk. (2001), juga mengatakan bahwa pemilihan lokasi yang baik, merupakan keputusan yang sangat penting pertama, karena keputusan lokasi mempunyai dampak yang permanen dan jangka panjang, apakah lokasi tersebut telah dibeli atau hanya disewa. Kedua, lokasi akan mempengaruhi pertumbuhan usaha dimas mendatang, lokasi yang dipilih harus mampu mengalami pertumbuhan ekonomi sehingga usahanya dapat berjalan. Terakhir, apabila nilai lokasi memburuk akibat perusahaan lingkungan yang dapat terjadi setiap waktu, mungkin saja usaha tersebut harus dipindahkan atau ditutup. Kemudian menurut Gitosudarmo (2002:42), potensi pasar sangat mempengaruhi pemilihan lokasi penjualan dalam mencapai tujuannya. Menurut pendapat Sopiah (2008:139-140) ada tiga indikator yang mencirikan lokasi penjualan, yaitu; (a) letak berdirinya tempat berjualan, (b) transportasi umum, dan (c) lalu lintas kenderaan.

Faktor penting lainnya yang perlu dipertimbangkan perusahaan untuk menarik minat konsumen adalah kualitas produk. Suatu produk harus mengutamakan kualitas. Menurut Tjiptono (2000:4) kualitas adalah suatu kondisi dinamis yang berhubungan dengan produk dan jasa,manusia proses dan lingkungan yang memenuhi atau melebihi harapan. Sedangkan Menurut Kotler (2007:180) kualitas adalah keseluruhan ciri serta sifat barang dan jasa yang berpengaruh pada kemampuan memenuhi kebutuhan 
yang dinyatakan maupun yang tersirat. Kemudian menurut Lupiyodi (2001:44) "kualitas adalah keseluruhan ciri-ciri dan karakteristik dari suatu produk atau jasa dalam hal kemampuannya untuk memenuhi kebutuhankebutuhan yang telah ditentukan atau bersifat laten. Produk adalah seperangkat atribut baik berwujud atau tidak berwujud, yang meliputi masalah warna, keistimewaan, dan daya tahan produk

Menurut Handoko (2010) kualitas ditentukan oleh sekumpulan kegunaan dan fungsinya, termasuk di dalamnya daya tahan, ketidaktergantungan pada produk lain atau komponen lain, eksklusifitas, kenyamanan, wujud luar (warna, bentuk, kemasan, dan sebagainya). Karena kualitas salah satu faktor yang dipertimbangkan konsumen sebelum membeli suatu produk. Disamping itu, menurut Ferrinadewi, E. (2006) salah satu cara memenangkan persaingan adalah melakukan diferensiasi produk, di mana diferensiasi yang efektif adalah dengan memperbaharui atribut produk yang merupakan harapan konsumen.

Menurut Kotler (2002: 329) kualitas barang dapat dilihat melalui tujuh dimensi, yaitu; (a) bentuk (performance, (b) keistimewaan (features), (c) keandalan, (d) mutu kinerja, (e) daya tahan, (f) pelayanan, dan $(g)$ keindahan.

Dari hal-hal di atas dapat disimpulkan bahwa dalam menciptakan produk yang berkualitas perusahaan harus memperhatikan dimensi kualitass barang, agar setiap konsumen mendapatkan kepuasan terhadap produk yang diinginkannya. Jadi produk yang memiliki kualitas yang baik akan menciptakan kepuasan bagi konsumen yang baik pula. Menurut pendapat Kotler (2002: 329) ada tiga indikator yang mencirikan kualitas produk, yaitu; (a) bentuk (performance, (b) keistimewaan (features), (c) daya tahan (durability)

Berdasarkan informasi yang diperoleh konsumen atas suatu produk, tahap berikutnya bagaimana mengambil keputusan apakah membeli atau tidak membeli. Keputusan pembelian terhadap suatu produk pada dasarnya erat kaitannya dengan perilaku konsumen. Perilaku konsumen merupakan unsur penting dalam kegiatan pemasaran suatu produk yang perlu diketauhi oleh seorang produsen, karena produsen pada dasarnya tidak mengetahui mengenai apa yang ada dipikiran seorang konsumen pada waktu sebelum, sedang, dan setelah melakukan pembelian produk tersebut. Menurut Kotler (2001:97) ada empat faktor yang mempengaruhi perilaku konsumen dalam membeli atau mengkonsumsi suatu produk dan layanan, yaitu; (a) faktor Kebudayaan (Cultural Factors, (b) Faktor Sosial (Social Factors), (c) Faktor Pribadi (Personal Factors, (d) Faktor Psikologis (Psychological Factors.

\section{METODE PENELITIAN}

Penelitian ini dilakukan pada konsumen pembeli dodol di Desa Paya Perupuk Tanjung Pura Kabupaten Langkat. Populasi penelitian adalah jumlah konsumen 50 pedagang dodol rata-rata mingguan 7000 orang. Sampel sebanyak 99 orang yang ditentukan dengan Rumus Slovin dengan Margin of Max Error 10\%. Teknik 
pengumpulan data yang digunakan adalah angket atau instrumen, observasi dan wawancara. Skala pengukuran instumen yang digunakan adalah skala Likert dengan lima (5) option jawaban sangat setuju, setuju, ragu-rgau, tidak setuju, sangat tidak setuju. Skala Likert menurut Djaali (2007) dapat digunakan untuk mengukur sikap, pendapat, dan persepsi seseorang atau sekelompok orang tentang gejala atau fenomena.

\section{Variabel dan Definisi Operasional Penelitian}

Disajikan pada Tabel 1. dibawah ini:

Tabel 1. Variabel dan Definisi Operasional Penelitian

\begin{tabular}{|c|c|c|}
\hline Variabel & Definisi Operasional & Indikator \\
\hline Harga (X1) & $\begin{array}{l}\text { Persepsi konsumen terhadap } \\
\text { sejumlah uang yang dibayarkan untuk } \\
\text { mendapatkan dodol }\end{array}$ & $\begin{array}{ll}\text { - } & \text { Keterjangkau harga } \\
\text { - } & \text { Kesesuaian harga dengan } \\
& \text { kualitas produk } \\
\text { - } & \text { Daya saing harga } \\
\text { - } & \\
& \text { Kesesuaian harga dengan } \\
& \text { manfaat }\end{array}$ \\
\hline $\begin{array}{l}\text { Lokasi } \\
\text { Penjualan } \\
\text { (X2) }\end{array}$ & $\begin{array}{l}\text { Tempat usaha pedagang dodol } \\
\text { berjualan yang dikaitkan dengan } \\
\text { transportasi }\end{array}$ & $\begin{array}{l}\text { - Letak berdirinya tempat } \\
\text { berjualan } \\
\text { - Transportasi umum } \\
\text { - Lalu lintas kendaraan }\end{array}$ \\
\hline $\begin{array}{l}\text { Kualitas } \\
\text { Produk } \\
\text { (X3) }\end{array}$ & $\begin{array}{l}\text { Kemampuan produk untuk } \\
\text { melaksanakan fungsinya sesuai } \\
\text { dengan keinginan konsumen }\end{array}$ & $\begin{array}{l}\text { - Bentuk } \\
\text { - Keistimewaan } \\
\text { - Daya tahan }\end{array}$ \\
\hline $\begin{array}{l}\text { Keputusan } \\
\text { Pembelian } \\
\text { (Y) }\end{array}$ & $\begin{array}{l}\text { Pengambilan keputusan dalam } \\
\text { membeli dodol yang dimulai dari } \\
\text { pengenalan masalah, pencarian } \\
\text { informasi, evaluasi alternatif, } \\
\text { membuat keputusan pembelian dan } \\
\text { akhirnya merasa puas atau tidak puas. }\end{array}$ & $\begin{array}{l}\text { - Motivasi } \\
\text { - Persepsi } \\
\text { - Pembelajaran } \\
\text { - Keyakinan }\end{array}$ \\
\hline
\end{tabular}

Instrumen yang digunakan kualitas produk) dan variabel terikat mengambil data sebelumnya (keputusan pembelian) dengan rumus dilakukan uji validitas dan uji sebagai berikut:

reliablitas. Data ordinal
ditransformasi menjadi data interval dengan metode MSI dan sebelum dianalisis terlebih dahulu dilakukan uji normalitas, multikolinieritas, heteroskedastisitas, dan uji linieritas

\section{Analisis Data Penelitian}

Regresi Berganda

$$
\text { Analisis data pertama }
$$

digunakan regresi berganda (Multiple Linier Regresion) untuk mengetahui besarnya pengaruh antara variabel bebas (harga, lokasi penjualan dan

\section{Uji Hipotesis}

Uji hipotesis dilakukan dengan

uji statistik " $\mathrm{t}$ " yaitu untuk 
menunjukkan apakah harga, lokasi penjualan dan kualitas produk berpengaruh secara parsial terhadap keputusan pembelian. Sedangkan uji secara bersama digunakan uji F. Uji determinasi dilakukan dengan melihat koefisien $\mathrm{R}^{2}$. Kritetia penerimaan atau penolakan hipotesis ditentukan dengan kriteria;

a. Jika tingkat sig $(\alpha)<0,05$ atau $\mathrm{t}_{\text {hitung }}>\mathrm{t}_{\text {tabel }}$, maka $\mathrm{H}_{0}$ ditolak. b. Jika tingkat $\operatorname{sig}(\alpha)>0,05$ atau $\mathrm{t}_{\text {hitung }}<\mathrm{t}_{\text {tabel }}$, maka $\mathrm{H}_{0}$ diterima.

\section{HASIL PENELITIAN DAN PEMBAHASAN \\ Hasil Analisis Regresi Berganda}

Besarnya perubahan faktor dependen (Y) akibat perubahan pada faktor independen $\left(\mathrm{X}_{1}, \mathrm{X}_{2}, \mathrm{X}_{3}\right)$ dapat dijelaskan melalui persamaan regresi yang diperoleh. Hasil analisis data disajikan pada Tabel 2.

Tabel 2. Uji Regresi Linier Berganda

\begin{tabular}{|c|c|c|c|c|c|c|}
\hline \multicolumn{7}{|c|}{ Coefficients $^{a}$} \\
\hline \multirow{2}{*}{\multicolumn{2}{|c|}{ Model }} & \multicolumn{2}{|c|}{$\begin{array}{l}\text { Unstandardized } \\
\text { Coefficients }\end{array}$} & \multirow{2}{*}{$\begin{array}{c}\text { Standardized } \\
\text { Coefficients } \\
\text { Beta }\end{array}$} & \multirow[b]{2}{*}{$\mathrm{t}$} & \multirow[b]{2}{*}{ Sig. } \\
\hline & & B & Std. Error & & & \\
\hline \multirow[t]{4}{*}{1} & (Constant) & 13,547 & 2,463 & & 5,499 & ,000 \\
\hline & PersepsiHarga & ,461 & ,086 & ,491 & 5,387 & ,000 \\
\hline & LokasiPenjualan & ,087 & ,081 & ,091 & 1,064 & ,290 \\
\hline & KualitasProduk & ,268 & ,086 & ,259 & 3,133 & ,002 \\
\hline
\end{tabular}

a. Dependent Variable: KeputusanPembelian

Berdasarkan pada Tabel 2. diperoleh persamaan regresi sebagai berikut: $\mathrm{Y}=13,547+0,461 \mathrm{X}_{1}+0,087 \mathrm{X}_{2},+\mathbf{0 , 2 6 8 X _ { 3 }}+\mathrm{e}$ Dari persamaan regresi diketahui nilai konstanta 13,547 yang artinya jika harga, lokasi penjualan, dan kualitas produk 0 besarnya keputusan pembelian konsumen sebesar 13,547. Koefisien harga (X1) sebesar 0,461 artinya jika persepsi terhadap harga naik 1 satuan maka akan meningkatkan keputusan pembelian sebesar 0,484. Kemudian koefisien lokasi penjualan (X2) sebesar 0,087 artinya jika skor lokasi naik satu satuan maka keputusan pembelian akan meningkat sebesar 0,087. Demikian halnya pada kualitas produk koefisien sebesar 0,268, artinya jika kualitas produk naik satu satuan maka keputusan pembelian naik sebesar 0,268.

Selanjutnya hasil uji hipotesis secara parsial dapat diketahui dari Tabel 2.. Variabel harga dan kualitas produk berpengaruh positif dan signifikan terhadap keputusan pembelian karena nilai sig masingmasing $0,000<0,05$. Namun variabel lokasi penjualan tidak berpengaruh signifikan karena nilai sig $0,290>0,05$. Akan tetapi uji pengaruh variabel secara bersamasama, ketiga variabel bebas berpengaruh positif dan signifikan terhadap keputusan pembelian. Hasil perhitungan disajikan pada Tabel 3. 
Tabel 3. Hasil Uji Hipotesis Variabel Secara Bersama

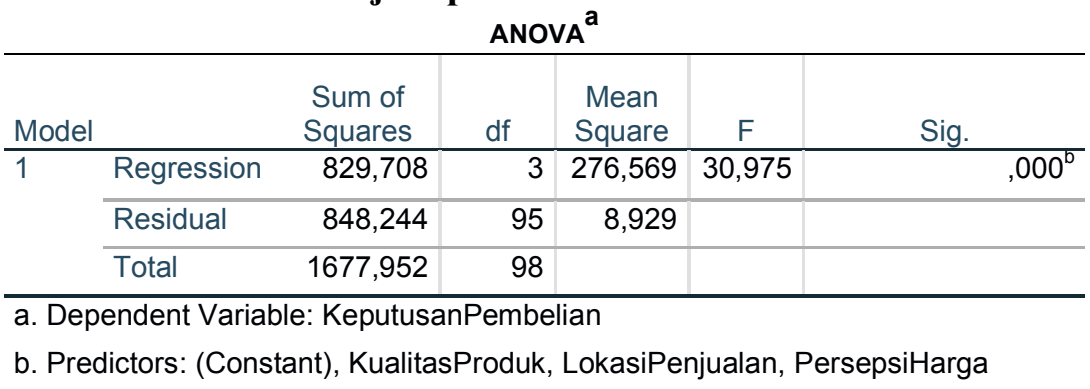

Tabel 4.. Model Summary

\begin{tabular}{lr|rrr}
\hline Model & $\mathrm{R}$ & $\mathrm{R}$ Square & $\begin{array}{c}\text { Adjusted R } \\
\text { Square }\end{array}$ & $\begin{array}{c}\text { Std. Error of } \\
\text { the Estimate }\end{array}$ \\
\hline 1 &, $703^{\mathrm{a}}$ &, 494 &, 479 & 2,98812 \\
\hline $\begin{array}{l}\text { a. Predictors: (Constant), KualitasProduk, LokasiPenjualan, } \\
\text { PersepsiHarga }\end{array}$
\end{tabular}

Selanjutnya untuk mengetahui besarnya kontribusi ketiga variabel dilihat dari $\mathrm{R}$ square yaitu sebesar 0,494 . Artinya variasi keputusan pembelian dapat dijelaskan ketiga variabel sebesar 49,4\%. Sedangkan sebesar $50,6 \%$ dijelaskan oleh variabel lain di luar model penelitian.

Hasil penelitian ini mendukung penelitian yang dilaksanakan sebelumnya seperti; Asri, dkk. (2015); Ong, I. A. (2013); Weenas JR (2013); Kodu, Sarini, (2013); Mariana (2015) secara parsial harga dan kualitas produk berpengaruh positif dan signifikan terhadap keputusan pembelian. Menurut Kodu, Sarini, (2013) harga merupakan variabel yang paling dominan mempengaruhi keputusan pembelian.

Selanjutnya penelitian yang hanya melihat pengaruh harga juga mendukung bahwa harga merupakan variabel yang berpengaruh positif dan signifikan terhadap keputusan pembelian (Antari, dkk. 2014; MeiYunita, S., \& Parjono, M. S. 2017). Harga merupakan variabel kunci yang menentukan keputusan konsumen membeli atau tidak membeli sesuatu. Karena konsumen akan selalu membandingkan produk yang diterima apakah sesuai atau sepadan dengan uang yang telah ia korbankan. Kensei, Z., \& Todd, S. (2003) menyatakan kesadaran harga sering diukur berdasarkan pengetahuan harga. Kesadaran harga dilihat dari tiga konstruksi yaitu; pengetahuan harga, pencarian harga di toko dan pencarian harga antara toko. Artinya konsumen sebelum membeli mereka mencari informasi apakah harga yang ditawarkan wajar, apakah sesuai dengan harga di toko dan membandingkannya dengan toko lain. Perbedaan harga antar toko akan mempengaruhi keputusan pembelian. $\mathrm{Wu}$, Kewen,( 2014) menyatakan dispersi atau perubahan harga berhubungan dengan niat membeli. Kemudian menurut Chang, T. Z., \& Wildt, A. R. (1994) harga yang dirasakan dan kualitas yang dirasakan mempengaruhi nilai yang dirasakan, dan nilai yang dirasakan adalah faktor 
utama yang mempengaruhi niat membeli.

Sejalan dengan harga, kualitas juga menjadi pertimbangan sebelum membeli. Hal ini diperkuat riset parsial Yazia, V. (2014) bahwa kualitas berpengaruh positif dan signifikan terhadap keputusan pembelian. Keputusan konsumen biasanya rasional, mereka bersedia membeli jika ia menganggap produk yang dibeli bagus. Kualitas bagus bisa karena memiliki bentuk atau kemasan yang unik, atau memiliki keistimewaan tersendiri. Dodol yang dibeli konsumen tidak hanya dimakan sendiri melainkan menjadi oleh-oleh khas. Produk dodol hampir ada disetiap daerah atau propinsi di Indonesia, akan tetapi setiap daerah memiliki ke-khasan tersendiri, baik dari bentuk, bahan atau rasa.

Secara parsial penelitian ini bahwa lokasi penjualan tidak berpengaruh terhadap keputusan pembelian. Perbedaan dengan riset yang lain disebabkan karena lokasi penjualan dodol di Desa Paya Perupuk Tanjung Pura Kabupaten Langkat umumnya dipinggir jalan utama yang dilalui kenderaan umum dan hanya sedikit yang masuk kedalam. Disamping itu, konsumen pada saat membeli dodol tidak memerlukan waktu yang lama sehingga tidak terlalu memperdulikan lokasi penjualan, berbeda jika membeli makanan dan dikonsumsi di tempat itu atau berbelanja yang lain yang membutuhkan waktu yang lebih lama.

Jika dilihat pengaruh variabel secara bersama-sama atau simultan antara variabel harga, lokasi penjualan, dan kualitas produk berpengaruh positif dan signifikan.
Hasil penelitian ini juga didukung penelitian sebelumnya yang dilakukan Hariadi, Doni,( 2012); Ghanimata, F., \& Kamal, M. (2012); Wijayanti \& Srihandayani (2015) bahwa lokasi, harga, kualitas produk berpengaruh terhadap keputusan pembelian.

\section{PENUTUP}

\section{Kesimpulan}

1. Persepsi terhadap harga berpengaruh positif dan signifikan terhadap keputusan pembelian

2. Lokasi penjualan tidak berpengaruh terhadap keputusan pembelian tingkat

3. Kualitas produk berpengaruh positif dan signifikan terhadap keputusan pembelian

4. Persepsi terhadap harga, lokasi penjualan dan kualitas produk secara bersama berpengaruh positif dan signifikan terhadap keputusan pembelian dodol.

\section{Saran}

Khusus penjual dodol harus mencari produsen yang menjual produknya dengan harga bersaing dan kualitas bagus. Bagi penjual dan sekaligus produsen dodol atau khusus produsen diharapkan lebih kreatif dalam memproduksi dodol misalnya dalam memilih atau menggunakan bahan baku selain beras ketan dan cara memproduksi untuk menekan biaya produksi. Pengemasan produksi juga perlu diperhatikan karena melekat pada kualitas produk dodol. Selanjutnya penjual dodol harus mampu mencari lokasi penjualan yang lebih strategis agar konsumen lebih tertarik untuk singgah dan melakukan transaksi pembelian 


\section{DAFTAR PUSTAKA}

Antari, K. R. M., Dunia, I. K., \& Luh Indrayani, S. P. (2014). Pengaruh Lokasi Dan Harga Terhadap Keputusan Berbelanja Pada Mini Market Sastra Mas Tabanan. Jurnal Pendidikan Ekonomi Undiksha, 4(1).

Asri Fajar, S., \& Aziz Fathoni, L. B. H. (2015). Pengaruh Harga, Kualitas Produk dan Promosi terhadap Keputusan Pembelian Lemari Es Merek LG di PT. Global Elektronik Banyumanik Semarang. Journal Management, 1(1). Binarupa Aksara.

Chang, T. Z., \& Wildt, A. R. (1994). Price, product information, and purchase intention: An empirical study. Journal of the Academy of Marketing science, 22(1), 16-27.

Djaali dan Muljono, P. 2007. Pengukuran Dalam Bidang Pendidikan. Jakarta. Grasindo

Ferrinadewi, E. (2006). Atribut Produk yang Dipertimbangkan dalam Pembelian Kosmetik dan Pengaruhnya pada Kepuasan Konsumen di Surabaya. Jurnal Manajemen dan kewirausahaan, 7(2), pp-139.

Ghanimata, F., \& Kamal, M. (2012). Analisis pengaruh harga, kualitas produk, dan lokasi terhadap keputusan pembelian (studi pada pembeli produk bandeng juwana elrina semarang)(Doctoral

dissertation,

Fakultas

Ekonomika dan Bisnis)..

Gitosudarmo, Indriyo, 2000.

Manajemen Pemasaran, Edisi

Pertama, Cetakan Ke-enam; Yogyakarta, Penerbit BPFE.
Grunert, K. G. (2005). Food quality and safety: consumer perception and demand. European review of agricultural economics, 32(3), 369-391.

Han, H., \& Ryu, K. (2012). The theory of repurchase decisionmaking (TRD): Identifying the critical factors in the postpurchase decision-making process. International Journal of Hospitality Management, 31(3), 786-797.

Handoko, T, Hani. 2010. Manajemen Personalia dan Sumber Daya Manusia (edisi 2). BPFE. Yogyakarta

Hariadi, D. (2015). Pengaruh produk, harga, promosi dan distribusi Terhadap keputusan pembelian konsumen Pada produk projector microvision. Jurnal Ilmu \& Riset Manajemen, 1(8). Kelompok Gramedia

Kensei, Z., \& Todd, S. (2003). The use of price in the purchase decision. Journal of empirical generalisations in marketing science, $8(1)$.

Kodu, S. (2013). Harga, kualitas produk dan kualitas pelayanan pengaruhnya Terhadap keputusan pembelian mobil toyota avanza. Jurnal EMBA: Jurnal Riset Ekonomi, Manajemen, Bisnis dan Akuntansi, 1(3).

Kotler, philip dan Amstrong, 2007. Dasar - dasar pemasaran Edisi Ke Sembilan, dan Amstrong. 2001. Prinsip-Prinsip Manajemen. Jilid 1, Edisi Kedelapan. Jakarta Erlangga. 
JURNAL PLANS

Penelitian Ilmu Manajemen \& Bisnis

ISSN: $1978-7057$

E-ISSN: 2527-306X

dan Amstrong. 2002.

Manajemen Pemasaran. Edisi Milenium. Jakarta:

Lamb, Charles W., Hair J.F, McDaniel Carl. 2001. Pemasaran. Jakarta. Salemba Empat.

Lupiyoadi, R. (2001). Edisi Pertama. Manajemen

Pemasaran Jasa: Teori dan Praktik.

Ma'ruf, Hendri. 2005. Pemasaran Ritel. Jakarta: PT. Gramedia Pustaka Utama

Mariana. 2015 "Pengaruh Kualitas Produk Dan Harga Terhadap Keputusan Pembelian Produk Pada industri UKM Amplang UD,Sinar Rejeki Di Samarinda”. eJournal Administrasi Bisnis,Vol.3. No. 2, Tahun 2015

MeiYunita, S., \& Parjono, M. S. (2017). PENGARUH DESAIN PRODUK DAN HARGA TERHADAP KEPUTUSAN PEMBELIAN MANIKMANIK DI DESA GAMBANG KECAMATAN GUDO KABUPATEN

JOMBANG. Jurnal Pendidikan Tata Niaga (JPTN), 1(1).

Ong, I. A. (2013). Analisa pengaruh strategi diferensiasi, citra merek, kualitas produk dan harga terhadap keputusan pembelian pelanggan di cincao station grand city, surabaya. Jurnal Strategi Pemasaran, 1(2), 1-11.

Setyawarman, A. (2009). Pola Sebaran dan Faktor-Faktor yang Mempengaruhi Pemilihan Lokasi Retail Modern (Studi Kasus Kota Surakarta) (Doctoral dissertation, UNIVERSITAS DIPONEGORO)

Sopiah, S. (2008). Manajemen Bisnis Ritel. Penerbit ANDI, Yogyakarta.

Staton, William J, Y. Lamarto. 2001. Prinsip Pemasaran. Jakarta: Erlangga

Swastha, Basu, \& Sukotjo. 2000. Manajemen Pemasaran Modern. Yogyakarta:

2000. Azas-azas Marketing. Yogyakarta: Liberty Tjiptono, F (2000). Manajemen Jasa I.Edisi Kedua Andi Offset. , Fandi dan Gregorius

Candra 2005. Manajemen Jasa. Yogyakarta: Andi Offset. , Fandy. 2000. Strategi

Pemasaran. Yogyakarta:

Penerbit Andi , Fandy. 2006. Service, Quality, \& Satisfication. Yogyakarta: Penerbit Andi

Weenas, J. R. (2013). Kualitas produk, harga, promosi dan kualitas pelayanan pengaruhnya terhadap keputusan pembelian Spring Bed Comforta. Jurnal EMBA: Jurnal Riset Ekonomi, Manajemen, Bisnis dan Akuntansi, 1(4).

Wijayanti, H., \& Srihandayani, C. M. (2015). PENGARUH LOKASI, HARGA, KUALITAS PRODUK, DAN PROMOSI TERHADAP KEPUTUSAN PEMBELIAN RUMAH SURODINAWAN GRANDSITE PADA PT. DWI MULYA JAYA

MOJOKERTO. Majalah Ekonomi, 20(1 Juli), 107-107.

$\mathrm{Wu}$, Kewen, Julita Vassileva, Yuxiang Zhao, Qinghua Zhu \& Jie Fang. (2014). The Influence 
JURNAL PLANS

Penelitian Ilmu Manajemen \& Bisnis

ISSN: 1978-7057

E-ISSN: 2527-306X

of Price Dispersion on Purchase Intention in Chinese Online C2C Market: a Trust Perspective, https://www.researchgate.net/publication/265013976-

The Influence of Price-

Dispersion on Purchase -

Intention in-

Chinese Online C2C -

Market a Trust Perspective
Yazia, V. (2014). Pengaruh Kualitas Produk, Harga dan Iklan terhadap Keputusan Pembelian Handphone Blackberry (Studi Kasus Blackberry Center Veteran Padang). JURNAL ECONOMICA: Research of Economic And Economic Education, 2(2), 165-173. 